\title{
An electrophysiological follow-up study on acquired unilateral nyctalopia
}

\begin{abstract}
Purpose To describe the clinical picture and electrophysiological findings in acquired unilateral nyctalopia.

Methods A patient who had acquired unilateral visual loss with normal fundus was followed for a period of 2.5 years with basic ophthalmological examinations including standard electroretinogram and photopic on and off responses.

Results A 46-year-old woman suffered from acquired unilateral nyctalopia. She complained of photopsia and blurred vision in her left eye. The initial examination of the left eye showed $1+$ cells in the anterior chamber and a granular appearance in the fovea. After 1 month of treatment she still complained of photopsia in her left eye. Ophthalmoscopy and fluorescein angiography revealed no abnormality in either eye. A bright flash electroretinogram (ERG) in the left eye was a negative shape. Photopic ERG elicited by a 150 ms stimulus showed a depressed $b$-wave and enhanced a- and d-waves in the left eye. Conclusions This ERG waveform suggested that the transmission between photoreceptor and on-bipolar cell might be affected by idiopathic retinal disease.
\end{abstract}

Key words d-wave, Nyctalopia, Off-response, On-bipolar cell, On-response, Photopic electroretinogram

A negative electroretinogram (ERG) in the darkadapted condition is a configuration in which the a-wave is normal and the b-wave is lower than the baseline, that is, the $b / a$ ratio is less than 1.0. This characteristic form is found in hereditary retinal dystrophy, ${ }^{1-7}$ retinal circulatory disturbances, ${ }^{8,9}$ and autoimmune retinopathies. ${ }^{10}$ In these retinal diseases negative ERG waveforms are caused by inner retinal dysfunction, especially in the bipolar cells. ${ }^{11,12}$

In this report, we describe a patient with acquired unilateral retinopathy who had a negative ERG waveform for 3 years.
Patient and methods

A 46-year-old woman had photopsia in her left eye in May 1994 and a month later visited an ophthalmologist. On examination, cells were found in the left anterior chamber, and she was treated with steroid for uveitis. In spite of the treatment, her left visual acuity decreased to 0.1 $(0.4 \times 1.25 \mathrm{D})$ and her pupillary light reflex was sluggish. She was referred to us in July 1995.

Our ocular examination showed a few cells in the left anterior chamber, clear media, and no fundus abnormalities ophthalmoscopically or by fluorescein angiography. Visual acuity was $0.5(1.0 \mathrm{X}-1.15 \mathrm{D})$ in the right eye and 0.2 $(0.9 \mathrm{X}-2.5 \mathrm{D})$ in the left. A relative afferent pupillary defect was found in the left eye. The patient continued to report difficulty with xanthopsia in the left eye. Humphrey perimetry of the left eye showed extensive, dense scotoma particularly in the nasal field, which showed absolute scotomas from $20^{\circ}$ outwards (Fig. 1). The critical flicker fusion frequency was normal in each eye. Dark-adapted threshold was tested at $15^{\circ}$ of the upper retina using a GoldmannWeekers adaptometer. The rod thresholds in the left eye were slightly higher than in the right eye, but they were within normal range. Colour vision tested with Ishihara plates, the Farnsworth-Munsell Panel D-15 test and desaturated Panel D-15 was normal bilaterally. Error scores on the Farnsworth-Munsell 100hue test were 60 in the right eye and 78 in the left eye, which were within normal range.

Pattern visual evoked cortical potentials (VECPs) were recorded with a silver-cup electrode placed at Oz. Checkerboard pattern stimuli were controlled on a black-and-white TV monitor. The mean luminance of the stimuli was $38 \mathrm{~cd} / \mathrm{m}^{2}$, and the contrast was $80 \%$. Check size and pattern field subtended 30 and $60 \mathrm{~min}$ and $7.5 \mathrm{deg} 15 \mathrm{~min} \times 11 \mathrm{deg}$ from a viewing distance of $170 \mathrm{~cm}$. The pattern reversed three times per second for transient VECP and 12 times per second for steady-state VECP. The preamplifier bandpass was $1-300 \mathrm{~Hz}$, and 100 responses were averaged. The patient fixed on the centre of the pattern monocularly with full refractive correction.

\section{K. Murayama Department of Ophthalmology Saitama Medical School Japan}

H. Kawabata E. Adachi-Usami Department of Ophthalmology Chiba University School of Medicine Japan

Koichiro Murayama, MD Department of Ophthalmology Saitama Medical School 38 Morohongo Moroyama-cho Iruma-gun Saitama 350-0495, Japan

Tel: +81492761250

Fax: +81492958002 e-mail:

koichiro@saitama.ac.jp

Presented at the annual meeting of the International Society for Clinical Electrophysiology of Vision (ISCEV), Monterey, California, 1997

Received: 22 December 1998 Accepted in revised form: 24 June 1999 

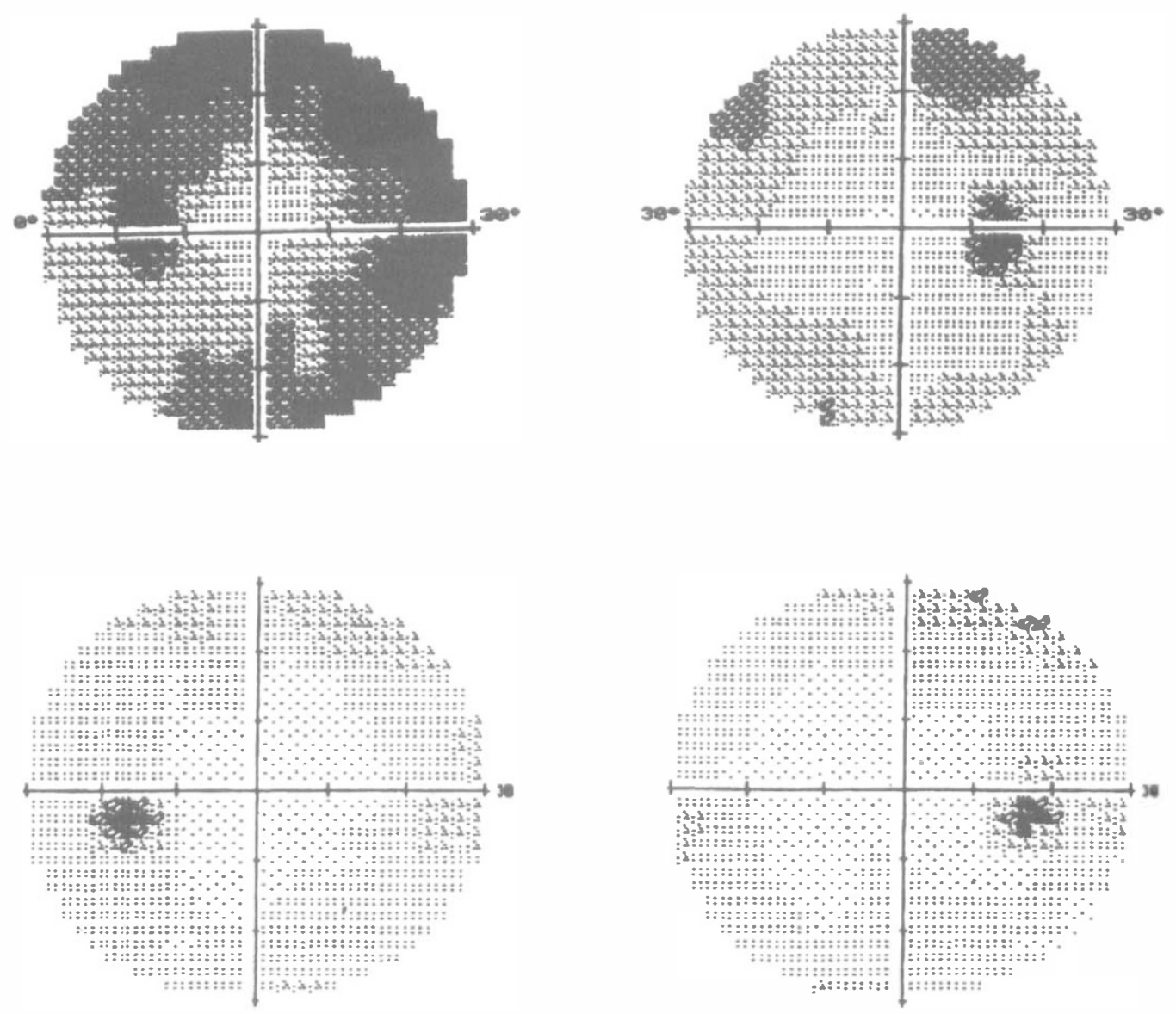

Fig. 1. Humphrey static perimetry (program 30-2). Top: first examination (18 October 1994). Bottom: 2.5 years after the first examination (3 March 1997).

\section{Electroretinography}

The full-field ERGs were recorded with Burian-Allen bipolar contact lens electrodes and an indifferent electrode on the earlobe. Pupils were dilated with $0.5 \%$ tropicamide and $0.5 \%$ phenylephrine hydrochloride. Full-field (ganzfeld) stimuli system (Model 2503B, LKC system, USA) were used for both test flashes and adapting background. The $125 \mathrm{~cd} / \mathrm{m}^{2}$ background was used and the white flash intensity was $4.6 \mathrm{~cd} / \mathrm{m}^{2}$ for recording brief flash photopic ERG. For recording the rod response, stimulus intensity was attenuated by Wratten neutral density filters. The extended duration stimulus (150 ms) for photopic ERG was provided by a $3300 \mathrm{~K}$ tungsten-halogen lamp and mechanical shutter (Copal, Japan) and delivered in the ganzfeld bowl. The intensity was able to be set by neutral density filters in 0.5 logarithmic scale steps.

The maximal ERG response was elicited by a $20 \mathrm{~J}$ xenon lamp delivered in the ganzfeld bowl. ERG responses were amplified with band pass $0.5-1000 \mathrm{~Hz}$, and averaged on a computer and stored. The maximal ERG response and rod response were recorded after 30 min of dark adaptation.

\section{Results}

The first electrophysiological examination was performed on 15 July 1994. The maximal ERG response was normal in the right eye and negatively shaped (normal a-wave and reduction of b-wave amplitude) in the left eye (Fig. 2). The b-wave amplitude of the right eye was normal in the scotopic ERG, while no b-wave was recorded in the left eye. The photopic ERG showed normal amplitude in both eyes with brief flash stimuli. The photopic ERG elicited by the $150 \mathrm{~ms}$ stimulus showed a depressed b-wave and enhanced a- and
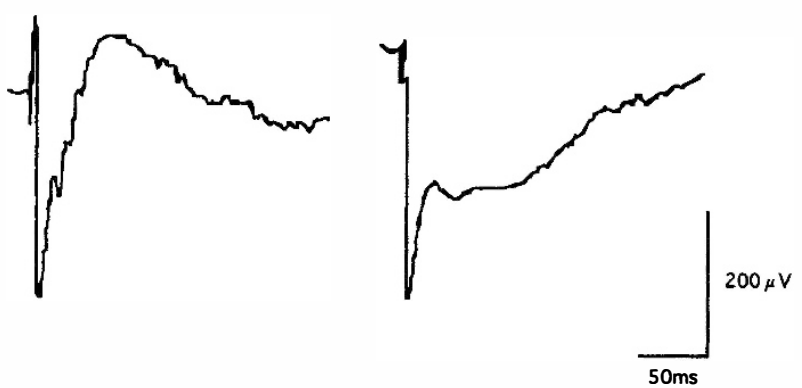

Fig. 2. The maximal electroretinogram (ERG) responses elicited by 20 $J$ xenon flash stimuli. The ERG waveform of the left eye was of the negative type (15 July 1994). 


\section{Brief flash stimulus}

$\mathrm{OD}$

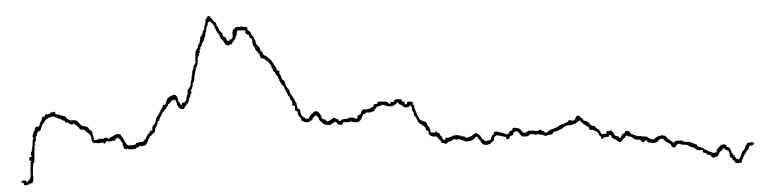

\section{0 ms duration stimulus}

$\mathrm{OD}$

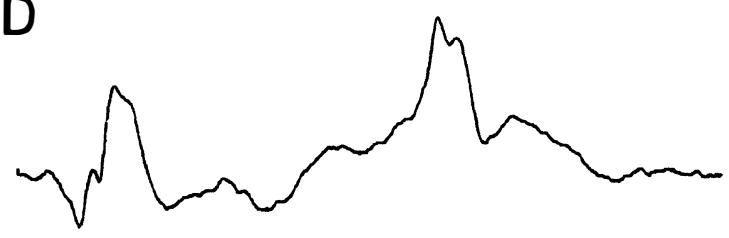

OS

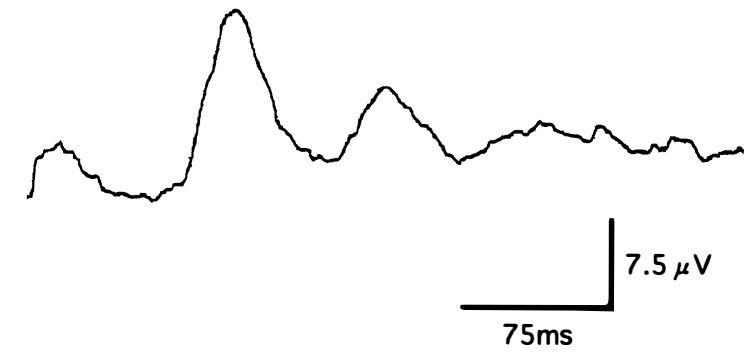

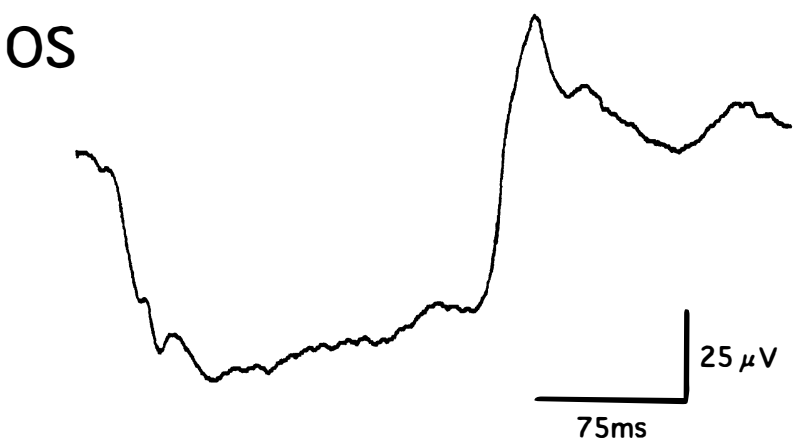

Fig. 3. Photopic ERGs (15 July 1994). Top: the ERG waveforms elicited by xenon brief flash stimuli in the left eye were similar to those in the right eye. Bottom: the ERG waveforms elicited by a $150 \mathrm{~ms}$ stimulus.

d-waves in the left eye (Fig. 3, Table 1). Pattern VECP with left eye stimulation showed a slight delay of the P100 component in a transient response. In a steady-state response the amplitude was reduced in the left eye to one-third of that in the right eye (Fig. 4).

The patient had showed normal visual acuity, while she had complained of xanthopsia and a little nyctalopia in her left eye since the onset of photopsia. Humphrey static perimetry on 3 March 1997 showed no abnormalities within the central $30^{\circ}$ in either eye (Fig. 1). On the other hand, the photopic ERG elicited by a $150 \mathrm{~ms}$ stimulus on 8 April 1996 showed a similar waveform in the left eye to that on 15 July 1994 (Fig. 5). On 8 March 1996 the amplitude was normal in a steady-state response and the implicit time of the P100 component in a transient response became normal (Fig. 6).

\section{Discussion}

We report a patient with a negative-type ERG which was not associated with congenital stationary night blindness (CSNB), X-linked congenital retinoschisis, central retinal artery occlusion, cone dystrophy or melanomaassociated retinopathy. Except for CSNB and melanomaassociated retinopathy, the other diseases can easily be diagnosed ophthalmoscopically. Usually ocular findings with $\mathrm{CSNB},{ }^{1-3}$ cone dystrophy ${ }^{8,9,13}$ and melanomaassociated retinopathy ${ }^{10,14}$ are found bilaterally.

In our patient, the negative waveform of the ERG was found only in the left eye, and ophthalmoscopically there were no abnormalities in either eye. This patient had no evidence of a systemic malignant disease during 3 years of follow-up.

Table 1. Electroretinographic amplitude of the patient

\begin{tabular}{lccc}
\hline & a-wave amplitude $(\mu \mathrm{V})$ & b-wave amplitude $(\mu \mathrm{V})$ & $\mathrm{d}$-wave amplitude $(\mu \mathrm{V})$ \\
\hline Bright flash ERG & & 359 & ND \\
$\quad$ Right eye & 261 & 164 & ND \\
$\quad$ Left eye & 328 & 37.3 & ND \\
Photopic ERG (xenon flash) & & 36 & ND \\
$\quad$ Right eye & 8 & & 35 \\
$\quad$ Left eye & 9.3 & 0 & 26.7 \\
Photopic ERG (150 ms duration) & 12.5 & 66.7 \\
$\quad$ Right eye & 41.7 & & \\
Left eye & & & \\
\hline
\end{tabular}

ND, not detected. 


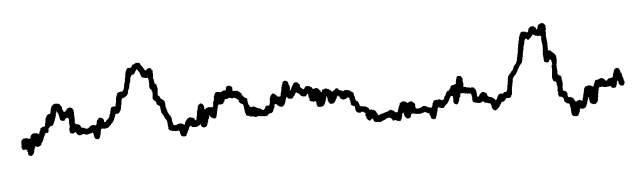

steady-state stimuli

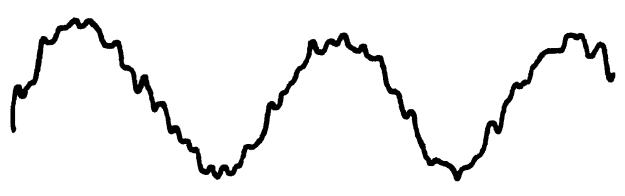

Fig. 4. Pattern visual evoked cortical potential (VECP): first examination (15 July 1994).
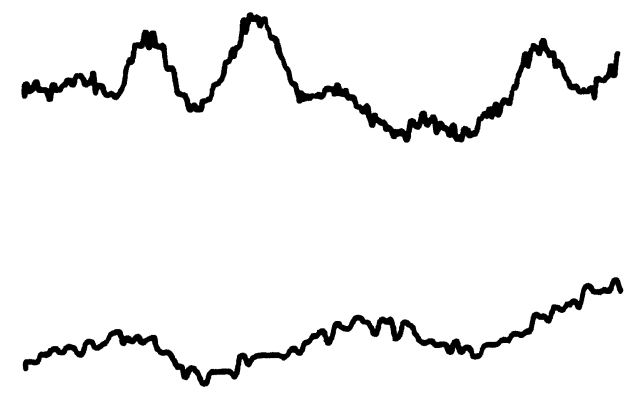

To our knowledge, this unilateral acquired negativetype ERG with normal fundus appearance may be a very rare condition. Previously, Ayaki et al. ${ }^{15}$ reported a patient with unilateral night blindness and a normal fundus. In that case the b-wave reduction and night blindness spontaneously improved within a year. Kelsey and Arden ${ }^{16}$ described two patients with unilateral loss of dark adaptation and reduced ERG b-wave amplitudes. Only one patient could be re-examined, and that patient showed a recovery of the ocular condition within 4 months. Fishman et al. ${ }^{17}$ however, reported a case that showed no recovery in the rod thresholds or in the abnormal ERG waveform during a 7 month follow-up.

Recent findings ${ }^{18-22}$ in retinal neurons have revealed that there are two major classes of cone bipolar cells and only one class of rod bipolar cell. Under photopic conditions, photoreceptors hyperpolarise in response to light, then on- and off-bipolar cells postsynaptic to the cones depolarise and hyperpolarise, respectively. The synapses of all bipolar cells appear to be glutaminergic. It is known that inner retinal activity, especially the on-bipolar cells, is reflected predominantly in the b-wave of the ERGs. ${ }^{11,23}$ Karwoski et al. ${ }^{11}$ revealed that the b- and $\mathrm{d}$-waves are generated primarily and directly by bipolar cells in the frog retina using the technique of currentsource density analysis. Blocking on bipolar cell activity in monkeys ${ }^{24}$ produces markedly reduced maximal $b$-waves and a lesser reduction in photopic b-waves, very similar to that in our patient. Psychophysical examination in primates showed ${ }^{25}$ that 2-amino-4phosphonobutyric acid (APB) produces a substantial loss in rod sensitivity but a comparatively small change in cone sensitivity. Psychophysical examinations in our patient revealed a slight abnormality in rod threshold but

\section{OD}
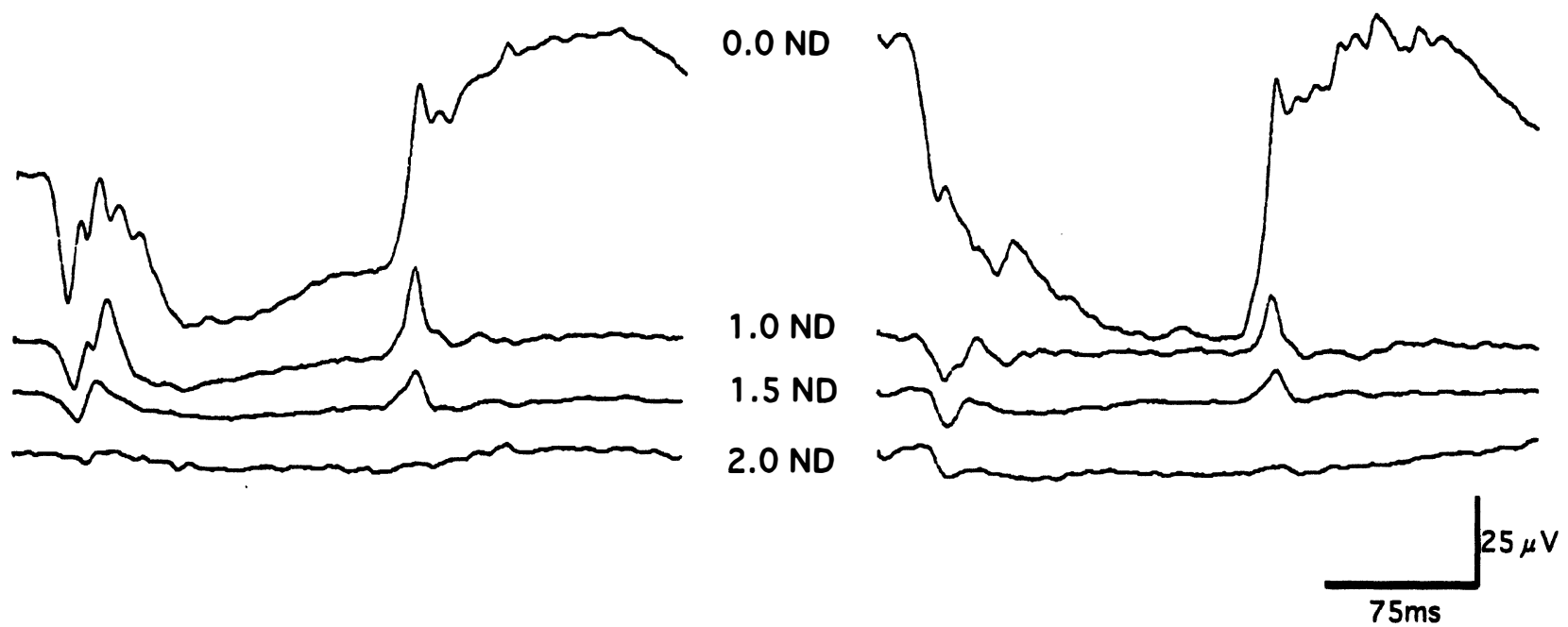

Fig. 5. Photopic ERGs elicited by a 150 ms stimulus, 2.5 years after the first visit (3 March 1997). 


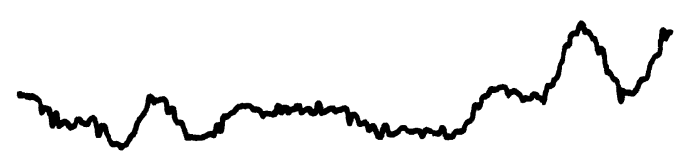

\section{steady-state stimuli}
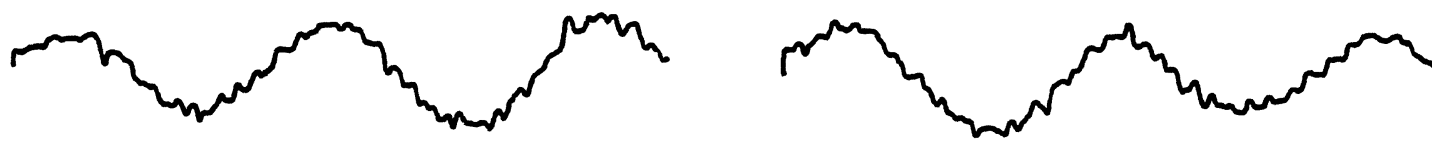

Fig. 6. Pattern VECP: 1.5 years after the first examination (8 March 1996).

no colour vision abnormality and no visual field sensitivity loss as seen with the Humphrey analyser (program 30-2).

With regard to the ERG waveform, our patient had suffered from on-bipolar dysfunction, but her psychophysical problem was diminished now. The signal processes in human light perception appear to be very complicated, and on- and off-channels complement each other after the signal travels through the bipolar cells in dark and light conditions.

Unfortunately, the cause of unilateral acquired negative ERG waveform is uncertain. The ophthalmological findings in our patient were related to macular oedema and anterior uveitis. Those ocular changes, however, disappeared within a month. But the xanthopsia and negative ERG waveform continued for 3 years. It may have been that the inflammatory changes in the retina caused depolarising bipolar cell dysfunction. We speculate that an inflammatory and perhaps an immune reaction against self-antigens or viral antigens may have been part of these ocular manifestations. ${ }^{26}$ Recently, several clinical reports of multiple evanescent white-dot syndrome (MEWDS) and acute zonal occult outer retinopathy (AZOOR) have been described in the literature. ${ }^{27-29}$ These diseases occurred in young and middle-aged, mostly female, patients and were characterised by unilateral idiopathic retinal and choroidal diseases with an abnormality in the ERGs. Gass $^{28,29}$ has hypothesised that these diseases represent parts of the spectrum of one disease, or are at least somehow linked. We think that our patient's condition could be distinguished from other idiopathic retinal diseases by ocular manifestations, especially the ERG. Precise ERG examination and general clinical and laboratory tests may help to diagnose this retinal disease whose aetiology is unknown.

The authors thank Maxine A. Gere for editing the manuscript.

\section{References}

1. Schubert VG, Bornschein H. Beitrag zur Analyse des menschlichen Elektroretinogramms. Ophthalmologica 1952;123:396-413.

2. Miyake Y, Yagasaki K, Horiguchi M, et al. Congenital stationary night blindness with negative electroretinogram. Arch Ophthalmol 1986;104:1013-20.

3. Miyake Y, Yagasaki K, Horiguchi M, et al. On- and offresponses in photopic electroretinogram in complete and incomplete types of congenital stationary night blindness. Jpn J Ophthalmol 1987;31:81-7.

4. Hirose T, Wolf E, Hara A. Electrophysiological and psychophysical studies in congenital retinoschisis of $X$-linked recessive inheritance. Doc Ophthalmol Proc Ser 1977;13:173-84.

5. Murayama K, Kuo CY, Sieving PA. Abnormal threshold ERG response in X-linked juvenile retinoschisis: evidence for a proximal retinal origin of the human STR. Clin Vision Sci 1991;4:317-22.

6. Miyake Y, Ichikawa K, Shiose $Y$, et al. Hereditary macular dystrophy without visible fundus abnormality. Am J Ophthalmol 1989;108:292-9.

7. Kellner U, Foerster MH. Cone dystrophies with negative photopic electroretinogram. Br J Ophthalmol 1993;77:404-9.

8. Karpe G. The basis of clinical electroretinography. Acta Ophthalmol Suppl 1945;24:1-45.

9. Ponte E. ERG and vascular disturbances: the clinical value of electroretinography. Proceedings of the 5th Symposium of the International Society for Clinical ERG 1968:303-11.

10. Singh AD, Milam AH, Shields CL, et al. Melanoma-associated retinopathy. Am J Ophthalmol 1995;119:369-70.

11. Karwoski CJ, Xu X, Yu H. Current-source density analysis of the electroretinogram of the frog: methodological issues and origin of components. J Opt Soc Am A 1996;13:549-56.

12. Knapp AG, Schiller PH. The contribution of ON-bipolar cells to the electroretinogram of rabbits and monkeys. Vision Res 1984;24:1841-6.

13. Miyake Y, Shiroyama N, Horiguchi M, et al. Bull's eye maculopathy and negative electroretinogram. Retina 1989;9:210-5.

14. Kellner U, Bornfeld N, Foerster MH. Severe course of cutaneous melanoma associated paraneoplastic retinopathy. Br J Ophthalmol 1995;79:746-52. 
15. Ayaki M, Oguchi $Y$, Matsuhashi M. Unilateral night blindness with normal fundus. Am J Ophthalmol 1984;98:630-2.

16. Kelsey JH, Arden GB. Acquired unilateral loss of dark adaptation. Br J Ophthalmol 1971;55:38-43.

17. Fishman GA, Alexander KR, Milam AH, et al. Acquired unilateral night blindness associated with a negative electroretinogram waveform. Ophthalmology 1996;103:96-104.

18. Massey SC. Cell types using glutamate as a neurotransmitter in the vertebrate retina. Prog Retinal Res 1990;10:399-426.

19. Slaughter MM, Miller RF. 2-Amino-4-phosphonobutyric acid: a new pharmacological tool for retina research. Science 1981;211:182-5.

20. Slaughter MM, Miller RF. The role of excitatory amino acid transmitters in the mudpuppy retina: an analysis with kainic acid and $N$-methyl aspartate. J Neurosci 1983;3:1701-11.

21. Evers HU, Gouras P. Three cone mechanisms in the primate electroretinogram: two with, one without off-center bipolar responses. Vision Res 1986;26:245-54.

22. Stockton RA, Slaughter MM. B-wave of the electroretinogram: a reflection of ON bipolar cell activity. J Gen Physiol 1989;93:101-22.
23. Hood DC, Birch DG. B wave of the scotopic (rod) ERG as measure of the activity of human on-bipolar cells. J Opt Soc Am A 1996;13:623-33.

24. Sieving PA, Murayama K, Naarendorp F. Push-pull model of the primate photopic electroretinogram: a role for hyperpolarising neurons in shaping the $b$-wave. Visual Neurosci 1994;11:519-32.

25. Smith EL, Harwerth RS, Crawford MLJ, et al. Contribution of the retinal ON channels to scotopic and photopic spectral sensitivity. Visual Neurosci 1989;3:225-39.

26. Mizener JB, Kimura AE, Adamus G, et al. Autoimmune retinopathy in the absence of cancer. Am J Ophthalmol 1997;123:607-18.

27. Jampol LM, Sieving PA, Pugh D, et al. Multiple evanescent white dot syndrome. 1. Clinical findings. Arch Ophthalmol 1984;35:2613-20.

28. Gass JDM. Acute zonal occult outer retinopathy. J Clin Neuro-ophthalmol 1993;13:79-97.

29. Gass JDM, Hamed LM. Acute macular neuroretinopathy and multiple evanescent white dot syndrome occurring in the same patients. Arch Ophthalmol 1989;107:189-93. 